\title{
Organic solvents and presenile dementia: a case referent study using death certificates
}

\author{
R R O'FLYNN, ${ }^{1}$ S M MONKMAN, ${ }^{2}$ H A WALDRON ${ }^{2}$ \\ From the Department of Psychiatry, ${ }^{1}$ UMDS (Guy's Campus), London SE1 9RT, and London School of \\ Hygiene and Tropical Medicine, ${ }^{2}$ London WCIE 7 HT, UK
}

ABSTRACT Occupational exposure to organic solvents has been implicated in the development of "presenile dementia" in several studies. The death certificates of all men aged under 65 dying in England and Wales bearing presenile dementia as cause of death were collected for the years 1970-9 $(\mathrm{n}=557)$ : control death certificates were obtained, matched for age and sex. No significant differences were found between the groups as regards estimated occupational exposure to either organic solvents or lead.

Several epidemiological studies, conducted for the most part in Scandinavia, have examined the relation between the occupational exposure to solvents of certain trades and the frequency with which individuals receive disability pensions for neuropsychiatric disorders. Some studies have suggested that the relative risk of receiving such pensions is increased in workers exposed to solvents by a factor of between 2 and $3 .^{1-3}$ Others have failed to detect similar increases in solvent workers except for some categories of neurosis. $^{4}$

Reports of groups of individuals attending occupational clinics have suggested that solvent workers in general, and house painters in particular, develop a characteristic syndrome which, with severe disturbances of memory, cognition, and behaviour, is said to be a dementing illness. ${ }^{56} \mathrm{~A}$ recent case referent study of men receiving diagnoses of dementia failed to find a statistically significant excess of solvent exposed workers compared with matched controls. $^{7}$

After an attempt to perform a case control study of Alzheimer's disease (which failed to recruit satisfactory numbers of subjects) (T D Browne et al, Medichem Conference, Ludwigshaven, 1986) we have examined the relation between the death certificate diagnosis of "presenile dementia" and the occupation for all men dying with this disease between 1970 and 1979 inclusive.

\section{Method}

Copies of death certificates bearing presenile demen-

Accepted 8 December 1986 tia or "Alzheimer's disease" as a cause of death were obtained for all men dying in England and Wales for the years 1970 to 1979 inclusive. In addition those dying from dementia before the age of 65 were included since, by definition, they had presenile dementia. For each case an age matched ( \pm 2 years) male control was drawn at random. There were 557 cases during this ten year period.

The death certificates record, in addition to general demographic data, the individual's most recent full time paid employment as reported to the Registrar at the time the death was registered.

Occupations of both subjects and controls were graded into one of three categories according to probable occupational exposure to organic solvents and to lead. These categories were "no exposure," "possible exposure," and "probable exposure" (see appendix 1).

This analysis of occupations was carried out by one of us (HAW) and, independently, by an occupational hygienist. Both were "blind" as to the cause of death on the death certificate. The exposure category was agreed before final allocation. We were particularly interested to see whether painters and decorators were more frequently represented among the cases than the controls since it is this group which has attracted most attention of late. As painters and decorators are likely to have, or to have had, exposure also to lead, which was formerly a common constituent of paints, we have also extended our inquiry to see whether or not there is any suggestion that lead may be associated with presenile dementia. The occupations were categorised with respect to lead exposure in the same way as for solvent exposure (see appendix 2). 


\section{Results}

A total of 557 pairs of death certificates was analysed. Thirty cases had possible exposure to solvents and 13 had probable exposure; the corresponding figures for the controls were 22 and 17 respectively (table 1 ). Among the group as a whole were 12 painters and decorators (six cases and six controls).

The number of cases and controls with probable or possible exposure to lead is shown in table 2 from which it may be seen that there were virtually no differences.

The relative risk (calculated using a matched pairs method) of dying from presenile dementia according to exposure to solvents or to lead is shown in table 3; there is no indication that exposure to either increases the risk of dying from presenile dementia.

In table 3 the relative risks are also shown after

Table 1 Occupational exposure to solvents

\begin{tabular}{lcc}
\hline No & Case & Control \\
\hline 0 & 514 & 518 \\
1 & 30 & 22 \\
2 & 13 & 17 \\
Total & 557 & 557 \\
\hline
\end{tabular}

$0=$ Occupation entails no exposure to solvents.

1 = Occupation entails possible exposure to solvents.

$2=$ Occupation entails probable exposure to solvents.

Table 2 Occupational exposure to lead

\begin{tabular}{lcc}
\hline No & Case & Control \\
\hline 0 & 539 & 547 \\
1 & 5 & 8 \\
2 & 13 & 12 \\
Total & 557 & 557
\end{tabular}

$0=$ Occupation entails no exposure to lead.

1 = Occupation entails possible exposure to lead.

$2=$ Occupation entails probable exposure to lead.

Table 3 Relative risks of presenile dementia with respect to exposure to solvents or lead. (Figures in parentheses are relative risks obtained after removal of subjects with specific defined diagnoses on the death certificate other than Alzheimer's disease)

\begin{tabular}{lcl}
\hline & $\hat{R}$ & $p$ \\
\hline Probable solvent exposure & $0 \cdot 76$ & NS \\
Possible solvent exposure & $1 \cdot 53$ & NS \\
& $(1.42)$ & NS \\
Total & $1 \cdot 14$ & NS \\
& $(1 \cdot 11)$ & NS \\
Probable lead exposure & 1.08 & NS \\
Possible lead exposure & $(1.00)$ & NS \\
Total & 0.63 & NS \\
& 0.90 & NS \\
\hline
\end{tabular}

exclusion of those subjects in whom a specific defined $\frac{\pi}{\Phi}$ pathological process, other than Alzheimer's disease,? was indicated on the death certificate; these included $\vec{F}$ Jacob-Creutzfeld disease, Pick's disease, and $\stackrel{\mathcal{O}}{+}$ Korsakoff's psychosis. Removing these subjects had? no effect at all on the relative risks.

\section{Discussion}

In this study we have been unable to show $\vec{b}$ significant difference between men receiving a deathcertificate diagnosis of presenile dementia and age् matched controls with regard to their estimated oco cupational exposure either to solvents or to lead. $A_{3}^{\mathbb{D}}$ similar result was obtained when those with firm specific pathological diagnoses were excluded from the study.

The major criticism of the use of death certificates in epidemiological research is that the diagnoseso recorded are imprecise. Several studies have compared certificated "indications of cause of death" with necropsy results and shown considerable discrep을. ancies between them (for example ${ }^{8-10}$ ). Whereasthere are several causes for this ${ }^{11} 12$ the only ones which might systematically distort the frequency with ${ }^{\mathrm{V}}$ which "dementia" is recorded is when an unrelatef process or unrecognised complication is proposed as an immediate cause of death and the chronic condi tion is completely omitted from the certificate.

A second difficulty arises in occupational epi $\frac{\mathbb{Q}}{2}$ demiology when death certificate diagnoses are re $\overrightarrow{\vec{F}}$ lated to the recorded occupation. In the Uniteof Kingdom the guidance for the registrar limits the recorded occupation to "the latest full time gainfuE employment followed by the deceased" with an indication if the individual was retired. As the Joint Res port of the Royal Colleges of Physicians and Pathologists noted, this often fails to specify the type of industry concerned and even more seriously mays completely ignore the main lifetime occupation. ${ }^{13}$ There is, however, no reason to suppose that such information is inaccurately recorded in a systematic way in either of the two groups under consideration indeed as Swanson and her colleagues showed the oc cupation given on the death certificate is certainlyos more accurate than that recorded in clinical records (if compared with that from interviews with relatives) and is correct in up to $80 \%$ of those dying under the age of $65 .^{14}$

In clinical practice the phrase presenile dementia has been used in three confusingly interrelated ways and these are presumably represented in the certificates' "causes of death."

Classically the term refers to cases of Alzheimer' disease, a primary degenerative condition of the brain? commonly presenting between the ages of 40 and 
$60^{15}$ : this shares histopathological features with "presenile dementia of the Alzheimer's type" and may be identical with it.

The difficulty of correctly diagnosing this condition has been recognised. Follow up studies from several London centres concluded that a number of "misdiagnoses" could be shown even after vigorous investigation ${ }^{16-18}$ : this has been confirmed by Neary and his colleagues in their recent studies of diagnostic brain biopsy. ${ }^{19}$ The major socioeconomic consequences of cognitive impairment (especially in men) in the age group under 65 ensure that detailed investigation is recognised as obligatory. Presenile dementia as an outcome to such assessment means "probable Alzheimer's disease."

Finally, the most frequent use is to describe any dementing illness occurring before the age of 65 -for example, one certificate in the present study reported "presenile dementia: Pick's disease."

The current form of the death certificate does not allow the clinical review that is necessary to distinguish these three uses let alone to validate the diagnoses themselves: no attempt was made to do so beyond the second analysis of the data being performed after the exclusion of those cases and their controls where defined pathologies or firm aetiologies were recorded.

The prevalence of dementia in the "presenium" is not known with any precision. The figure of $0.1 \%$ of the population aged between 45 and 64 as being afflicted by Alzheimer's disease quoted by Whalley et $\mathrm{al}^{20}$ is certainly higher than is to be expected from clinical practice and is perhaps the result of local environmental factors ${ }^{21}$ (although they specifically exclude lead as one of those factors). Our figures suggest that $0.02 \%$ of male deaths occurring in England and Wales are associated with presenile dementia: this compares favourably with that obtained by Chandra et al in their identically designed study of Alzheimer's disease. $^{22}$

The failure to show an excess of solvent exposed workers in those dying with a diagnosis of dementia compared with age matched controls contrasts with several epidemiological studies of the pension statistics in several countries ${ }^{1-3}$ but not with two of the recent case referent studies of Alzheimer's disease ${ }^{2324}$ where, similarly, no significant association could be shown. A prediction from such studies is that solvent workers would present more commonly with cognitive and neuropsychological impairment in death certificates.

Certainly in the United Kingdom there is no widespread awareness either in the medical profession or among workers exposed to solvents of the postulated link between organic solvents and neuropsychological disability and hence a source of bias probably oper- ating in Scandinavian studies may be discounted.

Given the rarity of presenile dementia and our failure to show an excess of solvent workers among those dying with dementia, two conclusions are possible which only further research can confirm or deny. The first is that organic solvents, if they exert any aetiological effect, do so either in a few individuals genetically susceptible or operate with other environmental agents in so subtle a manner as to be swamped by them. The alternative is that occupational exposure to organic solvents has no aetiological role at all in the development of dementia. On the whole, we tend towards the latter view.

\section{Appendix 1}

OCCUPATIONS WITH PROBABLE EXPOSURE TO SOLVENTS

Builder and decorator

Builders/decorators manager

Cabinet maker

Foreman coachpainter

French polisher

Journeyman (cabinet makers)

Master painter/decorator

Motor fitter

Paint sprayer

Paint tester

Painter and decorator

Screener (silk)

Signwriter and decorator

Signwriter/painter

Watchmaker

OCCUPATIONS WITH POSSIBLE EXPOSURE TO

SOLVENTS

Aero engine inspector

Aircraft fitter

Art teacher

Boiler stoker

Boot and shoe repairer

Boot and shoe operator

Builder

Builders manager

Cabinet maker

Carpenter

Carpenter and joiner

Communications engineer

Die polisher

Foreman finisher

Garage proprietor

Gear cutter

Handyman

Jeweller

Machine operator-rubber company 
Machine shop labourer

Master builder

Master printer

Metal polisher

Motor mechanic

Petrol pump attendant

Petrol station manager

Photocopier

Plastics engineer

Printer

Printing compositor

Process worker-plastics

Proprietor boot/shoe company

Rubber research operator

Rubber worker

School workshop technician

Sheet metal worker

Stenciller

Stereotyper

Vehicle mechanic

Warehouseman

\section{Appendix 2}

\section{OCCUPATIONS WITH PROBABLE EXPOSURE TO}

LEAD

Battery attendant

Battery worker

Master plumber

Plumber

Plumber and engineer

Plumbers mate

Scrapmetal merchant

Painter and decorator

\section{OCCUPATIONS WITH POSSIBLE EXPOSURE TO}

LEAD

Car factory worker

Engineers fitter

Garage proprietor

Machinist

Master printer

Motor car engine fitter

Petrol pump attendant

Petrol station manager

Precision engineer

Printer

Printers compositor

We are grateful to the Office of Population Censuses and Surveys for providing us with the death certificates. The study was supported by a grant from the European Chemical Industry Ecology and Toxicology Centre and the Paintmakers Association of Great Britain to whom we are very grateful.
References

1 Axelson $\mathrm{O}$, Hane $\mathrm{M}$, Hogstedt C. A case-referent study of. neuropsychiatric disorders among workers exposed to solvents Scand J Work Environ Health 1976;2:14-20.

2 Mikkelsen S. A cohort study of disability pension and deatio among painters with special regard to disabling pre-senil dementia as an occupational disease. Scand J Soc Med 1980;16 suppl 16:34-43.

3 Olsen J, Sabroe S. A case referent study of neuropyschiatric disor ders among workers exposed to solvents in the Danish wood industry. Scand J Soc Med 1980;16:suppl 16:44-9.

4 Lindstrom K, Riihimaki H, Hanninen K. Occupational solvent exposure and neuropyschiatric disorders. Scand J Work Environ Health 1984;10:321-3.

5 Arlien-Soborg P, Bruhn P, Gyldensted C, Melgaard B. Chronif్ట painters syndrome: chronic toxic encephalopathy in house painters. Acta Neurol Scand 1979;60:149-56.

6 Bruhn P, Arlien-Soborg P, Gyldensted C, Christensen EL Prognosis in chronic toxic encephalopathy: a two year followf up study in 26 painters with occupational encephalopathy. Actg Neurol Scand 1981;64:259-72.

7 Rasmussen H. Risk of encephalopathia among retired solvens workers. J Occup Med 1985;27:561-74.

8 Britton M. Diagnostic errors discovered at autopsy. Acta Me Scand 1974;196:203-10.

9 Medical Services Study Group of the Royal College of Psychiatrists. Death certification and epidemiological research Br Med J 1978;ii:1063-5.

10 Waldron HA, Vickerstaff L. Intimations of quality. London $\overrightarrow{0}$ Nuffield Provincial Hospitals Trust, 1977.

11 Aldersen MR, Baylis RIS, Clarke CA, Whitfield AGW. Death certification. Br Med J 1983;287:444-5.

12 Cochrane AL, Moore F. Death certification from the epidemio logical point of view. Lancet 1981;ii:742-3.

13 Joint Report of the Royal College of Physicians and the Roya College of Pathologists. Medical aspects of death certification $J$ R Coll Physicians London 1982;16:206-18.

14 Swanson GM, Schwarz AG, Burrows RW. An assessment of occupation and industry data from death certificates and hospi tal medical records for population-based cancer surveillance. Am J Public Health 1984;74:464-7.

15 Lishman WA. Organic psychiatry. Oxford: Blackwell, 1978.

16 Marsden CD, Harrison MJG. Outcome of investigation of patients with pre-senile dementia. Br Med J 1972;ii:249-52.

17 Nott PN, Fleminger JJ. Presenile dementia: the difficulties of early diagnoses. Acta Psychiatr Scand 1975;51:210-7.

18 Ron MA, Toone BK, Garralda ME, Lishman WA. Diagnosti accuracy in presenile dementia. Br J Psychiatr 1979;134:161-8.

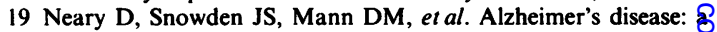
correlative study. J Neurol Neurosurg Psychiatry 1986;49: 229-37.

20 Whalley LJ, Caruthers AD, Collyer S, De May R, Frankievicz A응 A study of familial factors in Alzheimer's disease. $\mathrm{Br} D$ Psychiatry 1982;140:249-56.

21 Whalley LJ, Holloway S. Non-random geographical distributionof Alzheimer's presenile dementia in Edinburgh. Lancet 1985; 578.

22 Chandra V, Bharucha NE, Schoenberg BS. Conditions associ ated with Alzheimer's disease at death. Neurology 1986;36 209-11.

23 French RL, Schuman LM, Mortimer JA, Hutton JT, Boatma RA, Christians B. A case controlled study of dementia of the Alzheimer type. Am J Epidemiol 1985;121:414-21.

24 Arnaducci LA, Fratiglioni L, Rocca WA, et al. Risk factors foon clinically diagnosed Alzheimer's disease. Neurology 1986; 36:922-31. 